\title{
Validation of Noise Induced Hearing Loss Questionnaire Among Malay Sawmill Workers in Kelantan Malaysia
}

\author{
Razman MRa , Naing $L^{b}$, Aziah $D^{c}$ and Kamarul $I M^{c}$ \\ a Department of Community Health and Family Medicine, International Islamic University Malaysia, \\ ${ }^{b}$ Institute of Medicine, Universiti Brunei Darussalam, \\ c Department of Community Medicine, School of Medical Science, \\ Universiti Sains Malaysia
}

\begin{abstract}
Introduction: Exposure to excessive noise is the major avoidable cause of permanent hearing impairment. Sawmill is one of the workplaces where workers are exposed to hazardous noise level. This study was conducted to determine the reliability and validity of noise-induced hearing loss questionnaire among sawmill workers. Materials and Methods: This cross sectional study was conducted in March 2007 among 35 consented sawmill workers. A total of 40 items; 10 items for knowledge (8 areas), 20 items for attitude (7 areas) and 10 items for practice (2 areas) were assessed. Statistical analysis for reliability analysis was test by internal consistency and construct validity by exploratory factor analysis using principal components and Varimax rotation method. Results: Cronbach's alpha coefficients were acceptable for attitude (0.90) and practice (0.75). However, it was low for knowledge (0.67). Exploratory factor analysis showed three meaningful exploratory factors that could explain the three dimensions in the questionnaire. Conclusion: The results of the validation study suggested that the noise-induced hearing loss questionnaire is reliable and valid tool for assessing knowledge, attitude and practice among sawmill workers.
\end{abstract}

KEYWORDS: Reliability, validity, noise, questionnaire, sawmill workers

\section{INTRODUCTION}

Occupational noise induced hearing loss (NIHL) is considered one of the most common occupational disorder in industrial countries. ${ }^{1}$ This was confirmed by a study involving 22,000 randomly selected subjects in Great Britain which found that the prevalence of hearing loss and tinnitus increases with duration of occupational exposure to noise. ${ }^{2}$ Occupational NIHL accounted for more than four million disability adjusted life years (DALYs), all of them produced by the disability associated with the hearing loss. The number of DALYs was found to be greater in males than in females. ${ }^{3}$

Legislation is available but seldom enforced. Countries in South East Asia region, they generally have NIHL prevention program and legislation, unfortunately this is often poorly implemented and enforced; worst still the workers are ignorant of the problem. ${ }^{4}$ In Malaysia, workers are protected with the existence of such law and regulations for example, the Occupa-

Corresponding author;

Dr. Razman bin Mohd Rus, Department of Community Health and Family Medicine, International Islamic University Malaysia, 25200 Kuantan, Pahang, Malaysia.

e-mail: razman73@gmail.com tional Safety and Health Act 1994 and the Factory Machinery Act 1967 (Noise Regulations 1989). It has been clearly stated that among the issues to be covered in the training program includes: provisions of the regulation, the effects of noise on hearing, the purpose of hearing devices, the advantages, disadvantages and attenuation of various types of hearing protection devices, and instructions on their selection, fitting, use and care. ${ }^{5}$

Unfortunately, at present there was no published data regarding their knowledge, attitude and practice related to noise exposure at work place. Therefore, the present study aimed to validate the noise induced hearing loss questionnaire among sawmills workers in Kelantan, Malaysia in relation to their knowledge, attitude and practice.

\section{Materials and Methods}

A cross sectional study design was used in this study. It was conducted at a sawmill located in Rantau Panjang, Kelantan in March 2007 involving 37 sawmill workers. Universal sampling was applied to select the study subjects. The Bahasa Malaysia version of the Noise Induced Hearing Loss (NIHL) questionnaire was given to the respondents to fill after obtaining their written informed consent. The respondents were assured of anonymity and confidentiality of information. The questionnaire took 20 minutes to be completed. Returned questionnaires were checked on site by the 
researcher to ensure for completeness. Important issues like general aspects about noise, problems in workplace, causes of hearing loss, risk factors, signs and symptoms of noise induced hearing loss, treatment, prevention and law were included in the knowledge section. Whereas, the attitude section includes the general areas related to noise induced hearing loss, causes of hearing loss, signs and symptoms, health seeking attitude, prevention, law and risk taking attitude and lastly, preventive measures practiced at workplace and laws related to noise exposure at workplace were assessed in the practice section.

The self-administered Noise-Induced Hearing Loss (NIHL) questionnaire which was used was developed by the researchers based on reviewed literature. The face and content validity of the questionnaire were established by conducting a focus group discussion among the sawmill workers and followed with a oneday workshop involving several occupational health experts to discuss and review the issues brought up in the focus group discussion. The questionnaire was earlier pre-tested on respondents at different location that were not included in the final data collection.

It has two parts, namely the socio-demography and questions regarding knowledge, attitude and practice. Thirty six items of the NIHL questionnaire were selected. These items constituted a set of questions for the three domains of the NIHL questionnaire: knowledge (10 items), attitude (20 items) and practice (10 items). Categorical responses such as "betul" (true), "salah" (false) and "tidak tahu” (don't know) were used for knowledge items. As for attitude items, the responses were recorded using the Likert scale , ranging from 0 "sangat setuju"(strongly disagree) to 4 "sangat tidak setuju" (strongly agree) and as for practice, the responses were "tidak pernah"(never), "kadang-kadang" (seldom), "kerapkali"(frequent) and "sentiasa"(always).

Scores were calculated for each of the domain. For knowledge item, ' 2 ' marks for correct response, ' 1 ' mark for don't know, and no mark for incorrect response. For a positive attitude item, scores of ' 4 ', '3', '2', '1' and '0' for 'strongly agree', 'agree', 'neutral', 'disagree' and 'strongly disagree', respectively. For a good practice item scores '0', '1', '2' , and ' 3 ' were given for 'never', 'seldom', 'frequently' and 'always', respectively. The above scoring was reversed for negative attitude and practice item.

Data entry and analysis were done using SPSS version 12.7 Descriptive statistics were presented as tables to show frequency distribution of scores as well as their percentages. In this study, reliability analysis was used to assess the reliability of the questionnaire by looking at the Cronbach's alpha values. Cronbach's alpha was used to evaluate the internal consistency of the three domains in the questionnaire. It measures how well the items in the scale with unidimensional construct are inter-related and ranges in value from 0 to 1 , with higher value implying greater consistency.
Corrected item total correlation was also presented for each item. Items with item total correlation value of more than 0.3 were selected and items with item total correlation value of less than 0.3 will be reviewed. Cronbach's alpha value of more than 0.7 is generally considered to represent a measure of high internal consistency. ${ }^{8}$

In this study, factor analysis (using principal component method with Eigenvalues $>1$ and rotated using the Varimax orthogonal method) was used to analyze the construct validity which examine an item performs well in the construct that they supposed to be and not involved in the other constructs. By using this method numerous variables or items that are intercorrelated can be condensed into fewer dimensions, called factors. The study protocol was approved by the Research and Ethics Committee, School of Medical Sciences, Universiti Sains Malaysia on 1st August 2006

\section{Results}

\section{Demographic characteristics}

A total of 37 sawmill workers participated in this study. All participants were Malays and males were predominant. The mean age was $35 .^{2}(\mathrm{SD}=8.38)$ years. The median income per month was Ringgit Malaysia (RM) $350(I Q R=550)$ and the median duration of working was $11.1(\mathrm{IQR}=6.84)$ years. Majority of them were married (91.9\%) and smokers (83.8\%).

Table II, Table III and Table IV showed the results of factor analysis with all 36 items of the 3 domains; knowledge, attitude and practice. The first factor was associated with attitude. All items belonging in this domain were loaded with factor ranging from 0.30 to 0.85 . Meanwhile all items for knowledge and practice were loaded on the second and third factor.

The corrected item-total correlations of all items and Cronbach's alpha coefficients of three domains were shown in Table V. The Cronbach's alpha coefficients were acceptable for knowledge $(0.67)$, attitude $(0.90)$ and practice $(0.75)$. All corrected item-total correlations for knowledge and practice were greater than 0.30 indicating that each scale of the items had good correlation with their domain score which comprised of other items. For the attitude domain, although Cronbach's alpha coefficient for attitude was 0.90 , one of the item-total correlations was 0.21 and this suggests a low inter-item correlations.

\section{Discussion}

The Noise Induced Hearing Loss (NIHL) questionnaire used in this study was developed by the researchers based on reviewed literature therefore this study sought to determine the feasibility of assessing workers knowledge, attitude and practice through this self-administered questionnaire.

Reliability in defined as the consistency or the repro- 
ducibility of measurement over time.8 In general, the Cronbach's alpha coefficients were satisfactory ranging from 0.67 (knowledge) up to 0.90 (attitude). All corrected item total correlation were above the minimum recommended level of 0.20 to be included in a scale, with the exception of those for Q14 which was slightly above $(0.21)$. Overall, this showed good internal reliability and demonstrated the homogeneity of items.

Validity is the degree to which an instrument measures the construct it is intended to measure. Because of the absence of a gold standard the validity was expressed in terms of construct validity, which concerns the extent to which a particular measure relates to other measures consistent with theoretically derived hypotheses for the constructs that are being measured. Construct validity of the NIHL questionnaire was determined using factor analysis. In this study, factor analysis was performed and showed that all items of the NIHL questionnaire were loaded on three factors which correspond closely to the theoretical constructs of the NIHL questionnaire that is knowledge, attitude and practice. ${ }^{9,10}$

Results from the reliability and factor analysis results were not compared to other studies as there was no data available elsewhere on this issue.

There are several limitations in this study. First, all the subjects were from ethnic Malays. Ethnic differences may play a role in creating differences in the factor pattern as well as reproducibility of the questionnaire. Secondly, the sample size was small and came from one sawmill therefore it is unknown how representative the workers of this factory were of the Kelantan sawmill workers in general. Finally, the validity studies conducted and reported in this paper are themselves preliminary in nature. Based on these findings, other investigators can employ this instrument with substantial confidence about the reliability of the scales. Further validity studies are necessary to complement the initial content validity and construct validity investigations reported here. It would be much more desirable to examine the validity and reliability of the questionnaire in a bigger sample size plus broader ethnic groups comprising Chinese, Indian and others as Malaysia is multiracial country.

In conclusion this study showed that the three domains of the NIHL were considered reliable and valid although further study needs to be conducted in order to improve it. Ethnic differences should be considered if our findings are to be generalized to the sawmill worker population in other settings.

\section{Acknowledgments}

The authors would like to acknowledge Universiti Sains Malaysia (USM) for the Short Term Research Grant (No. 304/PPSG/6131504) and the Department of Community Medicine, School of Medical Sciences, Universiti Sains Malaysia, Kelantan Health Campus for their as- sistance. Special thanks to the Research and Ethical Committee of Universiti Sains Malaysia for reviewing and approving this study. We would also like to thank all sawmill managers and workers for their cooperation in making this research project.

\section{REFERENCES}

1. Richard TR and Saeed SR. Sound, noise and the ear. In: Baxter P, Adams PJ, Tar-Ching A, Cockraft A, Harrington J, eds. Hunters's Disease of Occupations. 9th Edition. London: Arnold, 2000:283-99

2. K. T. Palmer, M. J. Griffin, H. E. Syddal, B. Pannet and D. Coggon. Occupational exposure to noise and hearing difficulties in Great Britain. Occup Environ Med 2001; 59:634-9

3. D. I. Nelson, R. Y. Nelson, M. C. Barrientos and $M$. Fingerhut. The global burden of occupational noise-induced hearing loss. Am J Ind Med 2005; 48:446-8

4. NIOSH. Proposed National Strategies For The Prevention Of Leading Work-Related Diseases And Injuries - Noise-Induced Hearing Loss. National Institute for Occupational Safety and Health,1989. DHHS (NIOSH) publi cation no 89-135.

5. Factories and Machinery Act and Regulations 1967 Act 139.12th Edition. MDC Publishers Printers Sdn Bhd: Kuala Lumpur, 2001.

6. Jackson CJ and Furnham A. Designing \& Analysing Questionnaires \& Surveys A Manual for Health Profesionals \& Administraion.2000.

7. SPSS Version 12, Chicago IL: SPSS Inc; 2003.

8. Field, A. Research Methods II: Reliability Analysis.[Online] [Accessed February 2008]' Available from World Wide Web: http:// www.statisticshell.com/reliability.pdf

9. Downing SM. Reliability: on the reproducibility of assessment data. Med Educ 2004; 38:1006-12

10. Kline P. The handbook of Psychological testing.Oxford: Routledge, 1999. 
Table I. Sociodemographic characteristics of sawmill workers $(n=37)$

\begin{tabular}{|c|c|c|c|}
\hline $\begin{array}{l}\text { Variables } \\
\text { Age (years) }\end{array}$ & freq- (\%) & $\begin{array}{l}\text { Mean } \\
\text { (SDa) } \\
35.2 \\
(8.38)\end{array}$ & $\begin{array}{l}\text { Median } \\
\text { (I.Q-Rb) }\end{array}$ \\
\hline \multicolumn{4}{|l|}{ Sex } \\
\hline $\begin{array}{l}\text { Male } \\
\text { Female }\end{array}$ & $\begin{array}{l}34(91-9) \\
3(8.1)\end{array}$ & & \\
\hline $\begin{array}{l}\text { Duration of } \\
\text { working (years) }\end{array}$ & & $\begin{array}{l}11.1 \\
(6.84)\end{array}$ & \\
\hline $\begin{array}{l}\text { Income (RM/ per } \\
\text { month) }\end{array}$ & & & $\begin{array}{l}\text { 350.00 } \\
\text { (550.00) }\end{array}$ \\
\hline \multicolumn{4}{|l|}{ Smoking status } \\
\hline Smoker & $31(83.8)$ & & \\
\hline $\begin{array}{l}\text { Non-smoker } \\
\text { Marital status }\end{array}$ & $6(16.2)$ & & \\
\hline Married & $34(91.9)$ & & \\
\hline Not married & $3(8.1)$ & & \\
\hline
\end{tabular}

a $S D=$ Standard deviation; ${ }^{\circ}$ I. Q. $R$ = interquartile range

Table II. Factor analysis for knowledge of NIHL questionnaire among sawmill workers $(n=37)$

Variable

Items

\section{Factor loadinga}

Factor Factor Factor

123

Hearing can deteriorate when sawmill workers are expose to

Q3 hazardous noise

0.61

Deafness can occur even if a worker is exposed to intermittent

Q4 noise for a long period

0.47

If people expose to noise, men are at higher risk to get deafness

Knowledge Q6 than women

0.54

Pus discharge from ear is an early sign of deafness due to

Q7 exposure to loud noise

0.56

Q8 Deafness due to noise can be treated by taking medicine

0.69

Deafness due to noise will recover back to normal if a person is

Q9 no longer exposed to noise

a Principal component analysis with Varimax rotation only items with factor loading more than 0.3 were shown 
Table III. Factor analysis for attitude of NIHL questionnaire among sawmill workers $(n=37)$

\begin{tabular}{|c|c|c|c|}
\hline \multirow{3}{*}{$\begin{array}{l}\text { Variable } \\
\text { Attitude }\end{array}$} & \multirow[b]{3}{*}{ Q1 } & \multirow{3}{*}{$\begin{array}{l}\text { Items } \\
\text { Sawmill workers will have deafness despite whatever preventive measures they } \\
\text { use }\end{array}$} & \multirow{2}{*}{$\begin{array}{l}\text { Factor loading } \\
\text { Factor } 1 \text { Factor } 2 \text { Factor } 3\end{array}$} \\
\hline & & & \\
\hline & & & \\
\hline & $\mathbf{Q 2}$ & I'm not bothered by noise in my workplace & 0.66 \\
\hline & Q3 & Exposure to noise while working in sawmill would not make me deaf & 0.59 \\
\hline & Q4 & $\begin{array}{l}\text { Imnot worried if I can't hear property or hearing burzing sound after working in } \\
\text { noisy places because it is only temporarily }\end{array}$ & 0.76 \\
\hline & Q5 & Excessive exposure to noise can cause permanent deafness & 0.55 \\
\hline & Q6 & I'm not worried if my hearing starts to deteriorate & 0.76 \\
\hline & $\mathbf{Q 7}$ & III seek traditional medicine if I have deafness in the early stage & 0.67 \\
\hline & Q8 & $\begin{array}{l}\text { I im not worried to get early treatment if I suspect of being deaf due to noise in } \\
\text { early stage because it is self-limiting }\end{array}$ & 0.51 \\
\hline & Q9 & Employer need not be informed if have hearing loss & 0.53 \\
\hline & Q10 & Preventive measures towards deafness due to noise in sawmill is important & 0.77 \\
\hline & Q11 & Weshould use the ear plug to avoid becoming deaf due to noise & 0.85 \\
\hline & Q12 & I like to use the ear plug & 0.8 \\
\hline & Q13 & Workers must accept whatever type of ear plug given to them & 0.41 \\
\hline & Q14 & Periodic audiometry assessment can detect deafness due to noise in workplace & 0.35 \\
\hline & Q15 & We should inform the employers if machine is noisier than before & 0.4 \\
\hline \multirow[t]{5}{*}{ Attitude } & Q16 & $\begin{array}{l}\text { Training and health education for workers regarding methods on self protection } \\
\text { towards noise should be done from time to time }\end{array}$ & 0.77 \\
\hline & Q17 & $\begin{array}{l}\text { Discusion with employer regarding noise at workplace wouldnit help to reduce } \\
\text { the occurence of deafness due to noise }\end{array}$ & 0.64 \\
\hline & Q18 & $\begin{array}{l}\text { Only employers need to know in detail about the Ocapational Safety and Health } \\
\text { Act } 1994\end{array}$ & 0.5 \\
\hline & Q19 & Noise at workplace is a usual thing for me & 0.43 \\
\hline & $\mathbf{Q 2 0}$ & It's easier to close the ear using finger/hand rather than wearing ear plug & 0.3 \\
\hline
\end{tabular}

${ }^{a}$ As per Table 2

Table IV. Factor analysis for practice of NIHL questionnaire among sawmill workers $(n=37)$

Q1 I use ear plug to protect my ear

Factor Factor Factor

Variable Items

1

23

Q2 I had ear examination done by doctor to detect deafness

0.55

due to noise NIHL

Q3 I always use ear plug while l'm working

0.49

Q4 I try to avoid noise as much as possible while I'm working

0.84

Q6 I discuss with my employers if ear plug is broken

0.42

Q7 Did you undergo periodic audiometry assessment once in

0.74

Practice every 2 years?

Q8 Has the employer arranged for workers to undergo

0.71 medical examination from time to time?

Q9 Have you attended any seminar or talk on deafness due to 0.76 noise?

Q10 Have your company conducted training session about safety and health? 
Table V. Item - total correlation and Cronbach's alpha coefficients for the NIHL questionnaire among sawmill workers $(n=37)$.

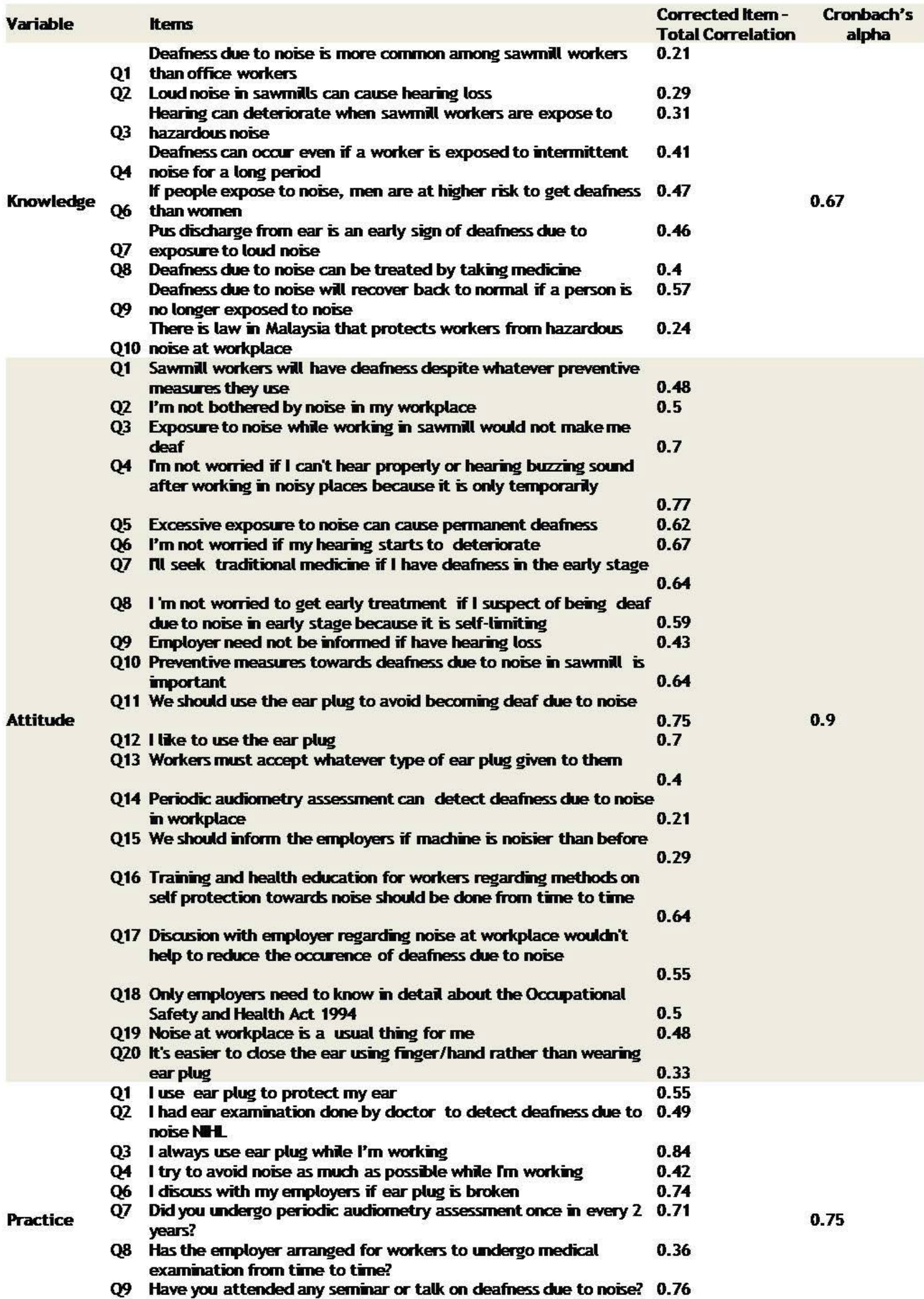

Q10 Have your company conducted training session about safety and health? 